\title{
Produção e valor nutritivo do capim-coastcross sob doses de nitrogênio e idades de rebrotação
}

[Production and nutritional value of bermudagrass $\mathrm{cv}$. coastcross grown under different nitrogen doses and regrowth ages]

\author{
M.A. Oliveira ${ }^{1}$, O.G. Pereira ${ }^{1}$, K.G. Ribeiro ${ }^{2}$, M.E.R. Santos $^{3}$, F.H.M. Chizzotti ${ }^{4}$, P.R. Cecon $^{1}$ \\ ${ }^{1}$ Universidade Federal de Viçosa \\ Av. P. H. Rolfs, $\mathrm{s} / \mathrm{n}$ \\ 36570-000 - Viçosa, MG \\ ${ }^{2}$ Universidade Federal dos Vales do Jequitinhonha e Mucuri - Diamantina, MG \\ ${ }^{3}$ Universidade Federal de Uberlândia - Uberlândia, MG \\ ${ }^{4}$ Universidade Federal de Lavras - Lavras, MG
}

\begin{abstract}
RESUMO
Avaliaram-se a produção e o valor nutritivo do capim-coastcross (Cynodon dactylon) sob cinco doses de nitrogênio - 0, 100, 200, 300 e 400kg/ha.ano - e duas idades de rebrotação - 28 e 42 dias. Os tratamentos foram arranjados em esquema fatorial, em blocos ao acaso, com três repetições. A adubação com nitrogênio (N) foi parcelada em três aplicações, realizadas logo após os cortes. A densidade populacional de perfilhos apresentou padrão de resposta quadrático em resposta à aplicação de $\mathrm{N}$. A produção de forragem do capimcoastcross variou de 8,0 a 17,2t/ha.ano para as doses de 0 a $400 \mathrm{~kg} / \mathrm{ha}$.ano de $\mathrm{N}$, apresentando resposta linear positiva com a adubação nitrogenada. Maiores valores de relação folha:colmo (RFC) foram obtidos em cortes mais tardios, na ausência de aplicação de N. Em geral, as doses crescentes de N diminuíram linearmente a RFC do capim-coastcross. A adubação nitrogenada aumentou linearmente os teores de proteína bruta (PB), observando-se maior eficiência de resposta na idade de 28 dias. Aumentos na digestibilidade in vitro da matéria seca em resposta à aplicação de doses crescentes de $\mathrm{N}$ somente ocorreram em plantas mais jovens, aos 28 dias de rebrotação. $\mathrm{O}$ teor de fibra em detergente neutro reduziu linearmente com a adubação nitrogenada. O efeito da adubação nitrogenada no valor nutritivo do capim-coastcross depende da idade de rebrotação dessa forrageira. Com a aplicação de maiores doses de $\mathrm{N}$ e sob condições favoráveis de crescimento, o pasto de capim-coastcross deve ser manejado com frequência de desfolhação de 28 dias.
\end{abstract}

Palavras-chave: Cynodon dactylon, digestibilidade, fibra em detergente neutro, número de perfilho, proteína bruta

\begin{abstract}
The production and nutritive value of the bermudagrass cv. coastcross under five different nitrogen doses ( 0 , 100, 200, 300 and 400kg/ha.year) and two regrowth ages (28 and 42 days) were evaluated. The experiment was arranged in a factorial scheme in a complete randomized block design with three repetitions. The nitrogen $(N)$ fertilization was performed in three applications right after harvest. Tiller population density showed quadratic response to $N$ application. The forage production varied from 8.0 to 17.2t/ha.year at $N$ doses ranging from 0 to $400 \mathrm{~kg} / \mathrm{ha}$.year, showing positive linear response to nitrogen fertilization. The highest values of leaf:stem relation (LSR) were observed for later harvest in the absence of $N$ fertilization. In general, as the $N$ doses increased the LSR of grass decreased linearly. The crude protein contents increased linearly with nitrogen fertilization, showing higher efficiency at 28 days of regrowth. In vitro digestibility increases regarding the $N$ fertilization occurred for younger plants at 28 days of regrowth. The neutral detergent fiber content decreased linearly with nitrogen fertilization. The nitrogen fertilization effect on the nutritional value of bermudagrass $\mathrm{cv}$. coastcross depends on the regrowth age of this forage. When applying higher $N$ doses under favorable growth conditions, the coastcross grass pasture should be managed to have defoliation each 28 days.
\end{abstract}

Keywords: Cynodon dactylon, digestibility, neutral detergent fiber, number of tiller, crude protein

Recebido em 31 de março de 2010

Aceito em 13 de abril de 2011

E-mail: m_rozalino@yahoo.com.br 


\section{INTRODUÇÃO}

De modo geral, as forrageiras do gênero Cynodon, como o capim-coastcross, possuem características produtivas e nutricionais que permitem elevada produtividade por animal e por área nos trópicos (Vilela et al., 2005), porém o padrão de resposta dessas gramíneas depende das condições de manejo a que são submetidas. Nesse sentido, a adubação nitrogenada e o intervalo de corte, que define a idade de rebrotação da planta, destacam-se como estratégias que modificam a produção e o valor nutritivo do pasto.

Dentre os nutrientes essenciais para as gramíneas forrageiras e nas condições edafoclimáticas do Brasil, o nitrogênio destaca-se pelos benefícios que causa à pastagem, por aumentar a produção de forragem (Rovetta, 2000; Santos et al., 2009) e melhorar o valor nutritivo do pasto, especialmente pelo incremento nos teores de proteína bruta da forrageira (Alves et al., 2001; Santos et al., 2009).

O intervalo de corte ou a idade de rebrotação da planta também determinam, ou condicionam a variabilidade dos indicadores de produção e da qualidade da forrageira adubada (Oliveira et al., 2000; Rovetta, 2000; Santos et al., 2009), o que torna relevante o seu estudo. De modo geral, pastos tropicais sob maiores idades de rebrotação apresentam maior produção de forragem por corte ou ciclo de pastejo, mas essa forragem tende a ser de mais baixo valor nutritivo. Contudo, resposta contrária tem sido verificada em pastos sob menores idades de rebrotação (Oliveira et al.; 2000; Tamassia et al., 2001; Santos et al., 2009).

Adicionalmente, é importante destacar que a análise dos estudos realizados com adubação nitrogenada em forrageiras tropicais (Alvin et al., 1996; Santos et al., 2009) tem indicado interação de dose de nitrogênio versus estratégia de manejo da desfolhação, de tal modo que seu efeito sobre as características produtivas e qualitativas do pasto é específico de acordo com as condições de ambiente e de manejo vigentes (Fonseca et al., 2008).
Diante do exposto, o objetivo deste trabalho foi avaliar a produtividade e o valor nutritivo do capim-coastcross sob distintas estratégias de adubação nitrogenada e idades de rebrotação.

\section{MATERIAL E MÉTODOS}

Este trabalho foi realizado entre novembro de 1999 e abril de 2000, em pasto de capimcoastcross (Cynodon dactylon (L.) Pers.), em Viçosa, MG cujas coordenadas geográficas são: $20^{\circ} 45^{\prime} \mathrm{S}, 42^{\circ} 51^{\prime} \mathrm{W}$ e $651 \mathrm{~m}$. A análise química do solo, classificado como podzólico vermelhoamarelo, de textura franco argiloarenosa, foi realizada no início do período experimental, na camada $0-20 \mathrm{~cm}$ de profundidade, e apresentou os seguintes resultados: $\mathrm{pH}$ em $\mathrm{H}_{2} \mathrm{O}$ : 5,8; $\mathrm{P}$ : 2,0 (Mehlich-1) e K: $103 \mathrm{mg} / \mathrm{dm}^{3} ; \mathrm{Ca}^{2+}: 2,5 ; \mathrm{Mg}^{2+}$ : $0,8 \mathrm{e} \mathrm{Al}^{3+}: 0,0 \mathrm{cmol}_{\mathrm{C}} / \mathrm{dm}^{3}(\mathrm{KCl} 1 \mathrm{~mol} / \mathrm{L})$.

Com base na análise química do solo, a calagem foi realizada superficialmente a fim de se elevar a saturação por bases para $60 \%$, com a aplicação de calcário dolomítico (PRNT = 80\%), 30 dias antes do período experimental. A aplicação do adubo fosfatado, em superfície e na dose de $100 \mathrm{~kg} /$ ha de $\mathrm{P}_{2} \mathrm{O}_{5}$, foi feita no dia 04/11/1999, usando como fonte o superfosfato simples. No corte de uniformização, bem como nos dois primeiros cortes subsequentes, foram aplicados $40 \mathrm{~kg} / \mathrm{ha}$ de $\mathrm{K}_{2} \mathrm{O}$, juntamente com a adubação nitrogenada, usando-se como fonte o cloreto de potássio.

Os dados climáticos registrados durante o período de avaliação estão na Tab. 1. A área experimental foi irrigada por sistema de aspersão quando ocorriam períodos de aproximadamente uma semana sem chuvas, objetivando-se evitar os efeitos desfavoráveis do veranico, muito comum na região durante os meses de janeiro e fevereiro, sobre o desenvolvimento da forrageira.

Foram avaliadas cinco doses de nitrogênio - 0, 100, 200, 300 e $400 \mathrm{~kg} / \mathrm{ha}$.ano de $\mathrm{N}$ - e duas idades de rebrotação - 28 e 42 dias -, usando-se o esquema fatorial $5 \times 2$, no delineamento em blocos ao acaso, com três repetições. A área experimental foi constituída de 30 parcelas (unidades experimentais), cada uma medindo $6 m^{2}(2 m x 3 m)$. 
Oliveira et al.

Tabela 1. Precipitação pluvial e médias de temperatura máxima, temperatura mínima, temperatura média e umidade relativa do ar, no período de novembro de 1999 a março de 2000

\begin{tabular}{lccccc} 
Mês/Ano & $\begin{array}{c}\text { Precipitação } \\
\text { pluvial }(\mathrm{mm})\end{array}$ & $\begin{array}{c}\text { Temperatura } \\
\text { máxima } \\
\left({ }^{\circ} \mathrm{C}\right)\end{array}$ & $\begin{array}{c}\text { Temperatura } \\
\text { mínima } \\
\left({ }^{\circ} \mathrm{C}\right)\end{array}$ & $\begin{array}{c}\text { Temperatura } \\
\text { média } \\
\left({ }^{\circ} \mathrm{C}\right)\end{array}$ & $\begin{array}{c}\text { Umidade } \\
\text { relativa } \\
(\%)\end{array}$ \\
\hline Novembro/1999 & 375,3 & 25,5 & 16,2 & 20,0 & 78,7 \\
Dezembro/1999 & 108,9 & 27,7 & 18,7 & 22,4 & 81,1 \\
Janeiro/2000 & 288,5 & 28,2 & 19,1 & 22,6 & 83,9 \\
Fevereiro/2000 & 148,2 & 28,9 & 18,6 & 22,6 & 82,9 \\
Março/2000 & 105,1 & 27,3 & 18,4 & 21,7 & 86,0 \\
Abril/2000 & 37,1 & 26,9 & 15,5 & 19,2 & 84,4 \\
\hline
\end{tabular}

As doses do fertilizante nitrogenado, na forma de sulfato de amônio, foram divididas em três aplicações durante o período experimental. Desse modo e de acordo com o tratamento, cada parcela recebeu $1 / 3$ da dose de nitrogênio preconizada - 0, 33, 66, 100 ou 133kg/ha de N por aplicação. A primeira aplicação do adubo nitrogenado ocorreu após o corte de uniformização (04/11/1999), enquanto a segunda e a terceira foram feitas após o primeiro e o segundo corte nas duas idades de rebrotação aos 28 e 42 dias (Tab. 2).

Nos dias das colheitas, a altura do capimcoastcross foi mensurada, previamente aos cortes, com régua graduada, tendo como critério a distância desde o nível do solo até as folhas localizadas na parte superior do dossel.

Na ocasião dos cortes e em cada parcela, a densidade populacional de perfilhos também foi determinada pela colheita de todos os perfilhos contidos no interior de um quadrado de $0,25 \mathrm{~m}$ de lado. Esses perfilhos foram acondicionados em sacos plásticos identificados, levados para o laboratório, onde foram quantificados. De posse desses valores, estimou-se o número de perfilhos por $\mathrm{m}^{2}$ em cada parcela, multiplicando-se o número de perfilhos presentes no interior do quadrado de área conhecida $\left(0,0625 \mathrm{~m}^{2}\right)$ por 16 .

Tabela 2. Datas dos cortes e alturas ao tempo do corte do capim-coastcross adubado com cinco doses de nitrogênio (N) e colhido aos 28 e 42 dias de rebrotação, durante a primavera e o verão

\begin{tabular}{ccc}
\hline Data do corte & $\begin{array}{c}\text { Idade } \\
\text { (dias) }\end{array}$ & $\begin{array}{c}\text { Altura }(\mathrm{cm}) \\
\mathrm{kg} / \text { ha.corte de } \mathrm{N} \text {, respectivamente }\end{array}$ \\
\hline $04 / 11 / 99^{*}$ & Uniformização & $05 ; 05 ; 05 ; 05 ; 05$ \\
$02 / 12 / 99^{*}$ & 28 & $15 ; 26 ; 27 ; 34 ; 35$ \\
$30 / 12 / 99^{*}$ & 28 & $21 ; 41 ; 53 ; 55 ; 54$ \\
$27 / 01 / 00$ & 28 & $22 ; 45 ; 47 ; 55 ; 56$ \\
$24 / 02 / 00$ & 28 & $19 ; 25 ; 27 ; 36 ; 39$ \\
$23 / 03 / 00$ & 28 & - \\
$20 / 04 / 00$ & 28 & - \\
$16 / 12 / 99^{*}$ & 42 & $28 ; 41 ; 55 ; 56 ; 61$ \\
$26 / 01 / 00^{*}$ & 42 & $38 ; 52 ; 61 ; 63 ; 62$ \\
$09 / 03 / 00$ & 42 & $39 ; 51 ; 60 ; 64 ; 63$ \\
$20 / 04 / 00$ & 42 & - \\
\hline
\end{tabular}

* Datas referentes à aplicação de 1/3 da dose de nitrogênio.

O restante da forragem, presente em $1,0 \mathrm{~m}^{2}$ de área útil no centro de cada parcela, foi colhido a $5 \mathrm{~cm}$ da superfície do solo. Este material, juntamente com a amostra destinada à contagem dos perfilhos, foi pesado em balança tipo dinamômetro, com divisão de 100g, e, posteriormente, uma subamostra de cerca de $250 \mathrm{~g}$ foi acondicionada em saco de papel, pesada novamente e colocada para secar em estufa de ventilação forçada a $65^{\circ} \mathrm{C}$. Com isso, foi possível determinar a produção de massa de forragem, expressa em matéria seca, por unidade de área.

Após pré-secagem, o material foi pesado e moído em moinho tipo Willey, com peneira de 30 mesh. Uma subamostra de aproximadamente $3 g$ de 
cada amostra moída foi seca em estufa a $105^{\circ} \mathrm{C}$, durante uma noite, a fim de se corrigir a estimativa do seu teor de matéria seca. Posteriormente, as amostras foram analisadas quanto aos teores de proteína bruta (PB), fibra em detergente neutro (FDN) e digestibilidade in vitro da matéria seca (DIVMS). As análises de PB foram realizadas pelo método semimicro Kjeldhal, utilizando-se fator 6,25 para conversão de nitrogênio total em $\mathrm{PB}$, como descrito por Silva e Queiroz (2002). A determinação da FDN foi feita pelo método descrito por Van Soest (1965), e a DIVMS pelo método de Tilley e Terry (1963).

As análises dos dados foram feitas usando-se o SAEG, (Euclides, 1993). Os dados de cada variável-resposta foram submetidos às análises de variância e de regressão. Para o fator idade, as médias foram comparadas utilizando-se o teste $\mathrm{F}$; para o fator dose de nitrogênio, ajustaram-se modelos de regressão, que foram escolhidos com base no coeficiente de determinação, na natureza do fenômeno em estudo e na significância dos coeficientes de regressão, testada pelo teste $\mathrm{F}$ a $10 \%$ de probabilidade.

\section{RESULTADOS E DISCUSSÃO}

De maneira geral, a adubação nitrogenada e a idade de rebrotação influenciaram o número de cortes realizados nas parcelas durante o período experimental (Tab. 3). A idade de 28 dias permitiu seis cortes nas parcelas que receberam 300 e $400 \mathrm{~kg} / \mathrm{ha}$.ano de $\mathrm{N}$, e a idade de 42 dias resultou em apenas quatro cortes para todas as parcelas. Observou-se menor número de cortes na idade de 42 dias, em comparação à idade de 28 dias. A menor frequência de corte, 28 dias, resultou em menor produção de forragem por corte, que foi compensada pela realização de maior número de cortes. A produção de forragem total variou de 5.456 a 15.480 e de 8.831 a $16.291 \mathrm{~kg} / \mathrm{ha}$.ano de MS, em plantas adubadas com 0 a $400 \mathrm{~kg} /$ ha.ano de $\mathrm{N}$ e colhidas aos 28 e 42 dias de rebrotação, respectivamente.

Independentemente da idade de rebrotação, a produção de forragem total do capim-coastcross aumentou $(\mathrm{P}<0,05)$ linearmente em função da dose de $\mathrm{N}$, segundo a equação de regressão $\hat{Y}=$ $7968,05+23,171 * * \mathrm{~N}\left(\mathrm{P}<0,01 ; \mathrm{R}^{2}=0,92\right) . \mathrm{A}$ eficiência de resposta ao $\mathrm{N}$ obtida neste trabalho - 23,2kg MS/kg N - é bem menor que as obtidas por Ribeiro (2000) e Alves et al. (2001), que trabalharam com o capim-tifton 85. Contudo, o valor de eficiência de conversão do $\mathrm{N}$-fertilizante em forragem foi próximo ao valor médio obtido em pastagens de gramíneas tropicais, que é de 26kg MS/kg de N (Martha Júnior et al., 2004). As equações de regressão permitiram estimar produções de forragem que variaram de 7,96 a 17,24t/ha.ano para as doses de 0 a $400 \mathrm{~kg} / \mathrm{ha}$.ano de $\mathrm{N}$, respectivamente.

Tabela 3. Produção de forragem (kg/ha de MS), por corte e total, do capim-coastcross em resposta às doses de nitrogênio em duas idades de rebrotação - 28 e 42 dias - no período de 04/11/1999 a 20/04/2000

\begin{tabular}{cccccccc}
\hline \multirow{2}{*}{$\begin{array}{c}\text { Nitrogênio } \\
\text { (kg/ha.corte) }\end{array}$} & Primeiro & Segundo & Terceiro & Quarto & Quinto & Sexto & Total \\
\cline { 2 - 7 }$y$ & \multicolumn{7}{c}{ Corte } \\
\hline 0 & 1187 & 1420 & 974 & 717 & 1158 & - & 5456 \\
33 & 1653 & 2629 & 2133 & 908 & 1369 & - & 8692 \\
66 & 2169 & 3837 & 3200 & 1127 & 1373 & - & 11706 \\
100 & 2313 & 3907 & 3056 & 1516 & 1918 & 2577 & 15287 \\
133 & 2336 & 3548 & 3043 & 1521 & 2159 & 2873 & 15480 \\
\hline 0 & 1686 & 2924 & 1945 & 2276 & - & - & 8831 \\
33 & 2436 & 4519 & 2717 & 2349 & - & - & 12021 \\
66 & 3328 & 5531 & 3851 & 2750 & - & - & 15460 \\
100 & 4508 & 5545 & 4054 & 2691 & - & - & 16798 \\
133 & 4462 & 5266 & 3894 & 2669 & - & - & 16291 \\
\hline
\end{tabular}


Segundo Santos et al. (2009), a adubação nitrogenada proporciona aumento na produção de forragem por promover alterações no número e no peso dos perfilhos. Realmente, em pastos com baixa população de perfilhos, a maior disponibilidade de $\mathrm{N}$ pode aumentar o número e o tamanho dos perfilhos até determinado valor, a partir do qual as plantas passam a competir entre si por fotoassimilados e, com isso, o número de perfilhos tende a diminuir.

De fato, o perfilhamento foi influenciado $(\mathrm{P}<0,05)$ pela dose de $\mathrm{N}$, e não foi alterado $(\mathrm{P}>0,05)$ pela idade de rebrotação (Tab. 4). Estimaram-se valores máximos de 3.065 e 3.010 perfilhos $/ \mathrm{m}^{2}$ no primeiro e terceiro cortes para as doses de 68,11 e 82,79 kg/ha.corte de $\mathrm{N}$, respectivamente. Estes valores assemelham-se ao observado para o segundo corte - 2.957 perfilhos $/ \mathrm{m}^{2}$. O maior número de perfilhos do capim-coastcross com a aplicação de $\mathrm{N}$ ocorreu em razão de o meristema apical ser um forte dreno de nutrientes, dentre os quais o $\mathrm{N}$, que desempenha importante papel na produção de novas folhas e perfilhos (Fagundes et al., 2006; Moraes et al., 2006).

Vale ressaltar que o $\mathrm{N}$ estimulou o perfilhamento a partir de gemas basilares e de rizomas, enquanto o surgimento de perfilhos aéreos, provenientes de gemas localizadas no estrato superior do perfilho principal, foi bastante reduzido ou praticamente nulo, provavelmente em decorrência do aumento nas condições de sombreamento dessas gemas, provocado pelo aumento na taxa de produção de folhas. Entretanto, doses altas de $\mathrm{N}$ - acima de $68 \mathrm{~kg} / \mathrm{ha}$.corte - reduziram o número de perfilhos por unidade de área, provavelmente devido à maior competição intraespecífica por assimilados produzidos pela planta como um todo.

Tabela 4. Equações de regressão ajustadas aos valores de densidade populacional de perfilho e relação folha:colmo do capim-coastcross em função das doses de nitrogênio (N)

\begin{tabular}{ccc}
\hline Corte & Equação & $\mathrm{R}^{2}$ \\
\hline 1 & Densidade populacional de perfilho (perfilho/m $\left.{ }^{2}\right)$ & 0,92 \\
2 & $\hat{Y}=2420,15+18,9294 * \mathrm{~N}-0,138950 * \mathrm{~N}^{2}$ & \\
3 & $\hat{Y}=2957,07$ & 0,85 \\
\hline 1 & $\hat{Y}=1684,34+32,0185 * \mathrm{~N}-0,193352 * * * \mathrm{~N}^{2}$ & 0,89 \\
2 & Relação folha/colmo & 0,80 \\
3 & $\hat{Y}=1,37981-0,00211485 * * \mathrm{~N}$ & 0,94 \\
\hline
\end{tabular}

$*$, **, *** Significativo a 5, 1 e $10 \%$ de probabilidade, respectivamente, pelo teste $\mathrm{F}$.

Independentemente das idades de rebrotação, a maior disponibilidade de $\mathrm{N}$ proporcionou redução $(\mathrm{P}<0,05)$ na relação folha:colmo $(\mathrm{RFC})$ (Tab. 4). No primeiro e segundo cortes, observaram-se reduções lineares na RFC, estimando-se valores de 1,38 a 1,10 e de 1,15 a 0,84 , para as doses de 0 a $133 \mathrm{~kg} /$ ha.corte de $\mathrm{N}$, respectivamente. No terceiro corte, observou-se efeito $(\mathrm{P}<0,05)$ quadrático, estimando-se valor mínimo de 0,98 para a dose de 92,04kg/ha.corte de N. A participação de folha no pasto em resposta à aplicação de $\mathrm{N}$ depende da estação do ano, em que, geralmente, seus valores são altos na estação seca e baixos no período chuvoso (Alvim et al., 1996). No período chuvoso, a adubação nitrogenada contribui para maior alongamento de colmo e, portanto, a maior produção de forragem ocorre concomitantemente ao decréscimo na RFC.

Valores reduzidos de RFC comprometem o valor nutritivo do pasto (Oliveira et al., 2000), porque o colmo verde possui pior valor nutritivo do que a folha verde (Santos et al., 2008). Em adição, o maior percentual de colmo no pasto prejudica sua estrutura, tornando-a desfavorável ao comportamento ingestivo e ao consumo animal (Carvalho et al., 2001). Contudo, é importante ressaltar que o colmo do capim-coastcross tem diâmetro reduzido e, assim, seu possível efeito prejudicial ao consumo animal deve ser minimizado, quando comparado às forrageiras 
que possuem colmos mais espessos. Os maiores valores de RFC ocorreram no terceiro corte, 1,50, na ausência de $\mathrm{N}$, em comparação com os valores obtidos no primeiro, 1,38, e segundo cortes, 1,15 (Tab. 4), o que coincidiu com o final do verão. Aumentos nos valores de RFC com a sucessão de cortes também foram observados por Ribeiro (2000) em capim-tifton 85.

Observou-se interação $(\mathrm{P}<0,05)$ de $\mathrm{N}$ versus idade de rebrotação para os teores de $\mathrm{PB}$ do capim-coastcross no primeiro, segundo e terceiro cortes (Tab. 5). De modo geral, comparando-se os teores médios de PB obtidos em cada dose de $\mathrm{N}$ no primeiro e segundo cortes, observaram-se valores mais altos aos 28 dias de rebrotação para as doses de 33, 66, 100 e 133kg/ha.corte de $\mathrm{N}$, ao passo que, no terceiro corte, valores mais elevados ocorreram com a aplicação das doses de 100 e 133kg/ha.corte de N (Tab. 5). Sob baixas doses de $\mathrm{N}$, o efeito da idade de rebrotação praticamente desaparece, o que pode ser decorrente do alto valor de RFC, nessa condição. A redução no teor proteico de gramíneas forrageiras do gênero Cynodon em função da idade de rebrotação também foi relatada por outros autores (Oliveira et al., 2000; Alves et al., 2001) e pode ser justificada pela menor RFC da forrageira em idade mais avançada (Oliveira et al., 2000), bem como pelo efeito de diluição desse nutriente na massa de forragem produzida.

Tabela 5. Valores observados para o teor de proteína bruta (\% MS) do capim-coastcross sob doses de nitrogênio $(\mathrm{N})$, colhido aos 28 e 42 dias de rebrotação e em três cortes

\begin{tabular}{|c|c|c|}
\hline \multirow{3}{*}{$\begin{array}{c}\text { Dose de N } \\
\text { (kg/ha.corte) }\end{array}$} & \multicolumn{2}{|c|}{ Idade de rebrotação (dia) } \\
\hline & 28 & 42 \\
\hline & \multicolumn{2}{|c|}{ Corte 1} \\
\hline 0 & 10,89a & $12,40 \mathrm{a}$ \\
\hline 33 & $19,21 a$ & $13,08 b$ \\
\hline 66 & $22,20 a$ & $17,53 b$ \\
\hline 100 & $25,16 a$ & $17,64 b$ \\
\hline 133 & $25,99 a$ & $19,33 b$ \\
\hline \multicolumn{3}{|c|}{ Corte2 } \\
\hline 0 & $10,70 a$ & 9,53a \\
\hline 33 & $14,58 a$ & $9,77 b$ \\
\hline 66 & $18,96 \mathrm{a}$ & $11,90 \mathrm{~b}$ \\
\hline 100 & $22,53 a$ & $13,58 b$ \\
\hline 133 & $23,25 a$ & $15,30 \mathrm{~b}$ \\
\hline \multicolumn{3}{|c|}{ Corte3 } \\
\hline 0 & 13,13a & $10,70 \mathrm{a}$ \\
\hline 33 & $13,50 a$ & $12,15 \mathrm{a}$ \\
\hline 66 & $16,90 a$ & $15,57 \mathrm{a}$ \\
\hline 100 & $21,14 a$ & $16,92 b$ \\
\hline 133 & 23,33a & $17,52 b$ \\
\hline
\end{tabular}

Médias seguidas por letras diferentes na mesma linha diferem entre si pelo teste $\mathrm{F}(\mathrm{P}<0,05)$.

Quanto ao efeito do N sobre os teores de PB do capim-coastcross, verificou-se que, além de resposta linear positiva, o coeficiente angular da equação de regressão ajustada foi mais alto na condição de 28 dias, em relação ao de 42 dias de rebrotação (Tab. 6). Isso demonstra que a eficiência da adubação nitrogenada em elevar o teor proteico é melhor quando a forrageira é submetida à maior frequência de cortes (28 dias). Em idades mais avançadas (42 dias), os menores teores de $\mathrm{PB}$ na forragem são, provavelmente, devido ao efeito da diluição do $\mathrm{N}$ na maior massa de tecido vegetal acumulada nesse período. Estes resultados estão de acordo com os obtidos por Ribeiro (2000), em capim-tifton 85. 
Tabela 6. Equações de regressão dos teores de proteína bruta (\% MS) do capim-coastcross, colhido em três cortes, aos 28 e 42 dias de rebrotação, em função da dose de nitrogênio (N)

\begin{tabular}{cclc}
\hline Corte & Idade de rebrotação (dia) & \multicolumn{1}{c}{ Equação } & $\mathrm{R}^{2}$ \\
\hline 1 & 28 & $\hat{Y}=13,4873+0,108477 * * \mathrm{~N}$ & 0,88 \\
1 & 42 & $\hat{Y}=12,33+0,05524 * * \mathrm{~N}$ & 0,90 \\
2 & 28 & $\hat{Y}=11,4181+0,09922^{* *} \mathrm{~N}$ & 0,96 \\
2 & 42 & $\hat{Y}=8,95078+0,04616^{* *} \mathrm{~N}$ & 0,96 \\
3 & 28 & $\hat{Y}=12,004+0,0843 * * \mathrm{~N}$ & 0,95 \\
3 & 42 & $\hat{Y}=10,9022+0,05523 * * \mathrm{~N}$ & 0,94 \\
\hline
\end{tabular}

** Significativo pelo teste $\mathrm{F}(\mathrm{P}<0,01)$.

No terceiro corte, as eficiências de 0,084 e $0,055 \%$ de $\mathrm{PB} / \mathrm{kg} \mathrm{N}$, estimadas para o capimcoastcross colhido aos 28 e 42 dias de rebrotação, respectivamente, foram maiores do que as obtidas por Ribeiro (2000), nas mesmas idades de rebrotação do capim-tifton 85 , sob doses de 0 a $100 \mathrm{~kg} / \mathrm{ha}$.corte de $\mathrm{N}$. A variação nos teores de $\mathrm{PB}$ na planta em resposta à adubação nitrogenada depende da dose de fertilizante aplicada, da frequência dos cortes, do genótipo, da forma de parcelamento do $\mathrm{N}$ e de fatores climáticos, que irão afetar o crescimento e o desenvolvimento da gramínea, determinando alterações no seu valor nutritivo.

As equações de regressão permitiram estimar teores de $\mathrm{PB}$ de 13,5 a $27,9 \%$ e de 12,3 a $19,6 \%$ - primeiro corte; de 11,4 a $24,6 \%$ e 9 a $15,1 \%$ segundo corte; e de 12,0 a 23,2 e 10,9 a 18,2,\% terceiro corte - para as doses de 0 a 133 $\mathrm{kg} /$ ha.corte de $\mathrm{N}$, aos 28 e 42 dias de rebrotação, respectivamente (Tab. 6). Estes valores estão bem acima do limite inferior de 7\%, proposto por Van Soest (1994) como necessário para manter as exigências nutricionais dos microrganismos ruminais.

Com relação ao teor de FDN, este não foi influenciado $(\mathrm{P}>0,05)$ pela idade de rebrotação, mas o foi $(\mathrm{P}<0,05)$ pela dose de $\mathrm{N}$, de forma linear negativa, segundo a equação $\hat{Y}=81,1617$ - 0,0498074*N $\left(\mathrm{P}<0,05 ; \mathrm{R}^{2}=0,79\right)$. De modo geral, ocorre ausência ou pequena resposta da adubação nitrogenada sobre os teores de FDN em gramíneas tropicais. Em trabalhos com gramíneas do gênero Cynodon, Alves et al. (2001), Johnson et al. (2001) e Rocha et al. (2001) verificaram redução nos teores de FDN com a aplicação de doses crescentes de $\mathrm{N}$. Contudo, Dias et al. (1996) e Marcelino et al.
(2002) não encontraram efeito da adubação nitrogenada nos teores de FDN em gramíneas do gênero Cynodon.

Um possível argumento para justificar o decréscimo do teor de FDN no capim-coastcross com a adubação nitrogenada pode ser encontrado no fato de o $\mathrm{N}$ estimular o crescimento das plantas e aumentar a utilização dos carboidratos disponíveis para síntese de células e de protoplasma, em vez de provocar o espessamento das paredes das células pelo acúmulo desses carboidratos (Black, 1968). Adicionalmente, a adubação nitrogenada pode reduzir a porcentagem de FDN na forrageira por estimular o crescimento de tecidos novos, que apresentam teores mais baixos de carboidratos estruturais na matéria seca (Corsi, 1984). Salienta-se, entretanto, que o efeito do $\mathrm{N}$ sobre os teores de FDN seja extremamente dependente das condições edafoclimáticas e de manejo.

O teor de FDN na forrageira apresenta alta correlação negativa com o consumo, quando se situa acima de 55 a 60\% (Van Soest, 1994). Apesar dos valores altos de FDN estimados no capim-coastcross - de 81,2 a $74,5 \%$ nas plantas adubadas com 0 e $133 \mathrm{~kg} /$ ha.corte de $\mathrm{N}-$, estes estão dentro da média geralmente registrada para gramíneas tropicais.

Quanto aos valores do coeficiente de DIVMS, constatou-se efeito $(\mathrm{P}<0,05)$ da interação $\mathrm{N}$ versus idade de rebrotação no primeiro corte. Neste, o coeficiente de DIVMS diferiu $(\mathrm{P}<0,05)$ entre as idades de rebrotação somente nas doses de 100 e $133 \mathrm{~kg} /$ ha.corte de $\mathrm{N}$, sendo mais alto $(\mathrm{P}<0,05)$ na idade de 28 dias do que na de 42 dias (Tab. 7). A menor digestibilidade do capimcoastcross aos 42 dias de rebrotação e sob doses 
elevadas de $\mathrm{N}$ está associada ao aumento nos constituintes da parede celular, principalmente a lignina (Oliveira et al., 2000), além da comum redução RFC da forrageira com a maior idade e sob condições nutricionais mais favoráveis ao crescimento.

Tabela 7. Coeficientes de digestibilidade in vitro da matéria seca do capim-coastcross sob doses de nitrogênio $(\mathrm{N})$ e colhido aos 28 e 42 dias de rebrotação

\begin{tabular}{ccc}
\hline Dose de $\mathrm{N}$ & \multicolumn{2}{c}{ Idade de rebrotação (dia) } \\
\cline { 2 - 3 } (kg/ha.corte) & 28 & $66,15 \mathrm{a}$ \\
0 & $66,75 \mathrm{a}$ & $64,31 \mathrm{a}$ \\
63 & $64,33 \mathrm{a}$ & $66,42 \mathrm{a}$ \\
100 & $69,62 \mathrm{a}$ & $64,52 \mathrm{~b}$ \\
133 & $72,34 \mathrm{a}$ & $64,18 \mathrm{~b}$ \\
\hline
\end{tabular}

Médias seguidas por letras diferentes na mesma linha diferem pelo Teste $\mathrm{F}(\mathrm{P}<0,05)$.

A adubação nitrogenada aumentou $(\mathrm{P}<0,05)$ os coeficientes de DIVMS das plantas mais jovens - com 28 dias de rebrotação -, e não influenciou $(\mathrm{P}>0,05)$ as plantas colhidas mais tardiamente com 42 dias de rebrotação (Tab. 7). Realmente, a DIVMS do capim-coastcross sob 28 dias de rebrotação aumentou $(\mathrm{P}<0,01)$ linearmente em função da dose de $\mathrm{N}$, ajustando-se à equação $\hat{Y}=$ $65,01+0,0647747 * N\left(P<0,01 ; R^{2}=0,80\right)$. Desse modo, estimaram-se valores de 65,0 a $73,6 \%$ de DIVMS nas forrageiras submetidas às doses de 0 e $133 \mathrm{~kg} /$ ha.corte de $\mathrm{N}$, respectivamente, e colhidas aos 28 dias de rebrotação. O aumento nos coeficientes de DIVMS com o aumento da dose de $\mathrm{N}$ pode ser explicado, parcialmente, pela redução nos teores de FDN com a adubação nitrogenada.

Aumento na digestibilidade com a aplicação de doses crescentes de $\mathrm{N}$ em cultivares do gênero Cynodon também foi observado por Johnson et al. (2001) e Alves et al. (2001). Entretanto, Dias et al. (1996), Ribeiro (2000) e Rocha et al. (2001) não observaram variação na DIVMS com a adubação nitrogenada. O efeito da adubação nitrogenada sobre a digestibilidade das gramíneas é inconsistente, em função da possível interação desta variável com outros fatores ambientais, além da idade de rebrotação.

De modo geral, os valores de DIVMS do capimcoastcross foram altos, variando de 54,7 a 73,5\% (Tab. 7) em função da idade de rebrotação e da dose de N. De fato, a digestibilidade média observada para gramíneas tropicais é da ordem de 55\% (Van Soest, 1994). A alta DIVMS do capim-coastcross justifica-se pelo fato de que a digestibilidade in situ da MS foi utilizada como critério de seleção desse genótipo em um programa de melhoramento realizado por Burton et al. (1967).

Pela análise conjunta dos dados (Tab. 3, 4, 5, 6 e 7), constata-se que pastos de capim-coastcross adubados com nitrogênio devem ser manejados de forma distinta em função da dose de $\mathrm{N}$ utilizada. Em verdade, a frequência de desfolhação, caracterizada neste trabalho pela idade de rebrotação, deve ser ajustada de acordo com a dose de $\mathrm{N}$ aplicada (Fonseca et al., 2008). Essa recomendação considera o efeito interativo das estratégias de manejo, adubação nitrogenada e idade de rebrotação, sobre as características do pasto, tal como observado nesse experimento (Tab. 5, 6 e 7).

Com efeito, para que se obtenha maior produção de forragem com melhora ou manutenção do seu valor nutritivo, recomenda-se que pastos de capim-coastcross, submetidos a altos níveis de adubação nitrogenada, durante os meses de primavera e verão, sejam manejados com maior frequência de desfolhação - 28 dias -, enquanto pastos sob doses mais baixas de $\mathrm{N}$ ou sem adubação nitrogenada podem ser manejados com desfolhação menos frequente, como 42 dias de rebrotação. 


\section{CONCLUSÕES}

A natureza da variação na densidade populacional de perfilhos do capim-coastcross, em função da adubação nitrogenada, depende da dose de nitrogênio aplicada. $O$ incremento na DIVMS do capim-coastcross em resposta à aplicação de doses crescentes de nitrogênio ocorre apenas quando se adota alta frequência de desfolhação. Com a aplicação de doses mais altas de nitrogênio e sob condições favoráveis de crescimento, o pasto de capim-coastcross deve ser manejado com frequência de desfolhação de 28 dias para conciliar maior produção de forragem com qualidade.

\section{REFERÊNCIAS BIBLIOGRÁFICAS}

ALVES, M.J.; PEREIRA, O.G.; CECON, P.R. et al. Rendimento forrageiro e valor nutritivo do capim-tifton 85 sob diferentes doses de nitrogênio, colhido ao atingir 30, 40 e $50 \mathrm{~cm}$ de altura. In: REUNIÃO ANUAL DA SOCIEDADE BRASILEIRA DE ZOOTECNIA, 38., 2001. Piracicaba. Anais... Piracicaba: ESALQ/USP, 2001.

ALVIM, M.J.; RESENDE, H.; BOTREL, M.A. Efeito da frequência de cortes e do nível de nitrogênio sobre a produção e qualidade da matéria seca do "coast-cross". In: WORKSHOP SOBRE O POTENCIAL FORRAGEIRO DO GÊNERO CYNODON, 1996, Juiz de Fora. Anais... Juiz de Fora: EMBRAPA-CNPGL, 1996. 181p.

BLACK, C.A. Soil-plant relationship. New York: John Wiley, 1968. p.507-557.

BURTON, G.W.; HART, R.H.; LOWREY, R.S. Improving forage quality by breeding. Crop Sci., v.7, p.329-332, 1967.

CARVALHO, P.C.F.; RIBEIRO FILHO, H.M.N.; POLI, C.H.E.C. et al. Importância da estrutura da pastagem na ingestão e seleção de dietas pelo animal em pastejo. In: REUNIÃO ANUAL DA SOCIEDADE BRASILEIRA DE ZOOTECNIA, 38., 2001, Piracicaba. Anais... Piracicaba: ESALQ, 2001. p.883-871.

CORSI, M. Effects of nitrogen rates and harvesting intervals on dry matter production, tillering and quality of the tropical grass Panicum maximum, JACQ. 1984. 125f. Thesis (Doctor) -, The Ohio State University, Ohio.
DIAS, P.F.; ROCHA, G.P.; OLIVEIRA, A.I. et al. Efeito de diferentes doses de nitrogênio sobre a disgestibilidade in vitro da matéria seca de três gramíneas forrageiras tropicais. Ciênc. Agrotec., v.20, p.108-113, 1996.

EUCLYDES, R.F. Sistema para análises estatísticas - SAEG. v.5.0. Viçosa: Funarbe, UFV, 1993.

FAGUNDES, J.L.; FONSECA, D.M.; MISTURA, C. et al. Características morfogênicas e estruturais do capim-braquiária em pastagem adubada com nitrogênio avaliadas nas quatro estações do ano. Rev. Bras. Zootec., v.35, p.21-29, 2006.

FONSECA, D.M.; SANTOS, M.E.R.; MARTUSCELLO, J.A. Adubação de pastagens no Brasil: uma análise crítica. In: SIMPÓSIO SOBRE MANEJO ESTRATÉGICO DA PASTAGEM, 4., 2008,Viçosa. Anais... Viçosa: UFV, 2008. p.295334.

JOHNSON, C.R.; REILING, B.A.; MISLEVY, P. et al. Effects of nitrogen fertilization and harvest date on yield, digestibility, fiber and protein fractions of tropical grasses. J. Anim. Sci., v.79, p.2439-2448, 2001.

MARCELINO, K.R.A.; VILELA, L.; LEITE, G.G. et al. Influência de nitrogênio e tensões hídricas sobre o valor nutritivo do Tifton-85 (Cynodon spp.), cultivado no cerrado. In: REUNIÃO ANUAL DA SOCIEDADE BRASILEIRA DE ZOOTECNIA, 39., Recife, 2002. Anais... Recife: UFRPE, 2002.

MARTHA JÚNIOR, G.B.; VILELA, L.; BARIONI, L.G. et al. Manejo da adubação nitrogenada em pastagens. In: SIMPÓSIO SOBRE MANEJO DA PASTAGEM, 21., 2004, Piracicaba. Anais ... Piracicaba: FEALQ, 2004. p.155-216.

MORAES, R.V.; FONSECA, D.M.; NASCIMENTO JÚNIOR, D. et al. Demografia de perfilhos basilares em pastagem de Brachiaria decumbens adubada com nitrogênio. Rev. Bras. Zootec., v.35, p.380-388, 2006.

OLIVEIRA, M.A.; PEREIRA, O.G.; GARCIA, R. et al. Rendimento e valor nutritivo do capim-tifton 85 (Cynodon spp.) em diferentes idades de rebrota. Rev. Bras. Zootec., v.29, p.1949-1960. 2000. (Suplemento 1)

RIBEIRO, K.G. Rendimento forrageiro e valor nutrtivo do capim-tifton 85, sob diferentes doses de nitrogênio e idades de rebrota, e na forma de feno, com bovinos. 2000. 107f. Tese (Doutorado) -, Universidade Federal de Viçosa, Viçosa, MG. 
ROCHA, G.P.; EVANGELISTA, A.R.; LIMA, J.A. Digestibilidade, teores de FDN e FDA de três gramíneas do gênero Cynodon. In: REUNIÃO ANUAL DA SOCIEDADE BRASILEIRA DE ZOOTECNIA, 38., 2001. Piracicaba,. Anais... Piracicaba: ESALQ/USP, 2001. Piracicaba,

ROVETTA, R. Morfogênese $e$ índices de crescimento do capim-tifton 85 (Cynodon spp.), sob diferentes doses de nitrogênio, colhido ao atingir 30, 40 e 50cm de altura. 2000. 56f. Dissertação (Mestrado) -, Universidade Federal de Viçosa, Viçosa, MG.

SANTOS, M.E.R.; FONSECA, D.M.; BALBINO, E.M. et al. Capim-braquiária diferido e adubado com nitrogênio: produção e características da forragem. Rev. Bras. Zootec., v.38, p.650-656, 2009.

SANTOS, M.E.R.; FONSECA, D.M.; EUCLIDES, V.P.B. et al. Valor nutritivo da forragem e de seus componentes morfológicos em pastagens de Brachiaria decumbens diferida. Bol. Ind. Anim., v.65, p.303-311. 2008.
SILVA, D.J.; QUEIROZ, A.C. Análise de alimentos: métodos químicos e biológicos. 3.ed. Viçosa: UFV, 2002. 235p.

TAMASSIA, L.F.M.; HADDAD, C.M.; CASTRO, F.G.F. et al. Produção e morfologia do capim de Rhodes em seis maturidades. Sci. Agric., v.58, p.599-605, 2001.

TILLEY, J.M.; TERRY, R.A. A two stage technique for the "in vitro" digestion of forage crops. J. Br. Grassl. Soc., v.18, p.104-111, 1963.

VAN SOEST, P.J. Nutritional ecology of the ruminant. Ithaca, NY: Cornell, 1994. 476p.

VAN SOEST, P.J. Symposium on factors influencing the voluntary intake of herbage by ruminants: voluntary intake in relation to chemical composition and digestibility. J. Anim. Sci., v.24, p.834-844, 1965.

VILELA, D.; PAIVA, P.C.A.; LIMA, J.A. et al. Morfogênese e acúmulo de forragem em pastagem de Cynodon dactylon cv. coastcross em diferentes estações de crescimento. Rev. Bras. Zootec., v.34, p.1891-1896, 2005. 